\title{
Correction to: A Novel Eutectic-Based Transdermal Delivery System for Risperidone
}

\author{
Faisal Al-Akayleh, ${ }^{1}$ Samer Adwan, ${ }^{2}$ Mai Khanfar, ${ }^{3}$ Nasir Idkaidek, ${ }^{1}$ and Mayyas Al-Remawi ${ }^{1,4}$
}

published online 29 December 2020

\section{Correction to: AAPS PharmSciTech volume 22, Article number: 4 (2021)} https://doi.org/10.1208/s12249-020-01844-4

In the proofing of the article, the authors changed the order of the captions of Figs. 10 and 11. However, the typesetter changed the captions without changing the diagrams, which led to mismatched diagrams and captions in Figs. 10 and 11.

In addition, the name and affiliation of the co-author Mai Khanfer requires the following change:

\section{Mai Khanfar}

Jordan University of Science and Technology, Department of Pharmaceutical Technology, Faculty of Pharmacy

The original article has been corrected.

Publisher's Note Springer Nature remains neutral with regard to jurisdictional claims in published maps and institutional affiliations.

The online version of the original article can be found at https:// doi.org/10.1208/s12249-020-01844-4

\footnotetext{
${ }^{1}$ Department of Pharmaceutics and Pharmaceutical Technology, Faculty of Pharmacy and Medical Sciences, University of Petra, Amman, Jordan.

${ }^{2}$ Department of Pharmaceutical Sciences, Faculty of Pharmacy, Zarqa University, Zarqa, Jordan.

${ }^{3}$ Department of Pharmaceutical Technology, Faculty of Pharmacy, Jordan University of Science and Technology, Irbid, Jordan.

${ }^{4}$ To whom correspondence should be addressed. (e-mail: malremawi@uop.edu.jo)
} 